\title{
UNA HISTORIA DE EMBARAZO ABDOMINAL
}

Por el Doctor Alfredo Londoño Upegui

Pereira - Caldas.

\section{Y. A. 38 años. Casada. O. D. Procd. Marsella (C.).}

Hereditarios: No.

Personales: Enfermedades de la infancia.

Obstétricos: Cesárea corporal y niño muerto por placenta previa el 20 de octubre del 51; además, tuvo un aborto de dos meses.

Ginecológicos: Menarquía a los 14 años, ciclo $3 / 28$, normal.

Resp.: Normal.

Circ.: Normal. Mx 12 Mn. 7. Tiene várices.

Dig.: Lengua saburral.

Nerv: Reflejos normales.

Organos de los sentidos: Normales.

Oseo y articular: Normal.

Estado físico general: Un poco enflaquecida.

Enfermedad actual. Llega a la sala el 14 de agosto del 53 por embarazo Al examen: altura uterina 30 , auscultación negativa, soplo uterino negativo.

A la palpación, no se aprecia presentación ni posición, sólo se palpa una masa y abdomen tenso.

Al tacto: cuello de multípara un poco blando y entreaabierto; vagina y puriné normales.

Al hacer la presión abdominal combinada al tacto, no logramos diferenciar la matriz de una tumoración abdominal. Fondos de saco ocupados.

Amígdalas: Normales.

Pelvimetría externa:

$\mathrm{BE}-24$.

$\mathrm{BC}-25$.

$\mathrm{BT}-28$.

$\mathrm{CE}-20$. 
Interrogatorio: Ultima regla el 15 de julio del 52, es decir, amonerrea de 13 meses. Viene al hospital por el médico de Marsella doctor José María Co rrea, para que se le resuelva el caso, pues según su opinión, el niño estaba muer to, y pasado el tiempo de nacer, segun palabras textuales de la enferma.

A] segundo mes de embarazo empezó a sentir náuseas, fatiga epigástrica, acedias, pertubaciones intestinales, anorexia, y notaba su salud, en general, dice la enferma, un poco mas rara que en los embarazos anteriores. Al sexto mes empezó a sentir movimientos y continuó sintiendo el niño hasta los siete meses y medio, cuando turo una pequeña hemorragia y ya no volvió a sentirlo más; de alli en adelante continuo menstruando cada mes.

Esta pequeña hemorragia de los siete meses y medio, ¿no correspondería a la expulsion de la caduca uterina:

En vista del cuadro y antecedentes se ordena una radiografía, la que indicó feto en el último trimestre del embarazo en presentación transversa según al radiólogo, doctor Isaac Bojanini.

Laboratorio:

Galli - Mainini - Negativo.

$\mathrm{RH}$ - Positivo.

Orina: Aspecto Turbio.

D $-1,20$

Alb. - No.

Azúcar - No.

Sed Eptls. - Abundantes.

Fórmula L.: Blancos -8.200 .

Nutr. -68 .

Eos. -2 .

Litocitos -29 .

Monacitos - 1 .

Hemograma. - Rojos- + millones 20.000 .

Hematocritos - 34 .

HB. -12 .

$\mathrm{PrC}-85$.

$\mathrm{PHC}-30$.

$\mathrm{CHB}-35$.

Glicemia -0.95 .

Azohemia - 0,48.

Coagulación White - 5'.

Sangría Duke -1 '.

Protrombina Quick - 15". 
Se procede a inducir el trabajo de la siguiente manera: 35 gramos de aceite de ricino, en ayunas, y dos horas más tarde $0,20 \mathrm{cgms}$ de quinina, la que se repitio una hora después; sonda intracervical, que no penetró, y taponamiento vacinal: pituitrina una ampolla en 250 c.c. de solución glucosa gota a gota intraxenoso.

Esto con el fin de hacer una versión o una embriotomía. Se fracasa.

En vista de ésto, al tercer día, 17 de agosto, se procede a la cesárea.

Opentción: Corte infra-umbilical para cesárea segmentaria, apertura de la i demás planos como de ordinario; al llegar a la cavidad encontramos saco tico a la vista, adherido al fondo uterino, parte externa, en donde penetraIo la capa muscular; de otra parte se insertaba al epiplón y al ligamento anmatriz un poco aumentada de volumen. Abrimos el saco de donde salió un hato turbio de regular cantidad sin mal olor. Extraemos el niño; desprende-
an saco de sus adherencias lo pediculizamos y cortamos todo el conjunto. I cesprenderlo del epiplón, hubo profusa hemorragia, la que logramos conteme con varias ligaduras; suturamos la herida del fondo de la matriz.

Al revisar, encontramos la trompa y el ovario intactos; la matriz normal, un poco aumentada de volumen, como ya sedijo.

Accidentes operatorios: Hemorragia del epiplón.

Cierre del peritóneo y demás planos como de ordinario.

Arestesia: Pentotal. Ciclopropano-éter-oxigeno.

Cirujano: Doctor Alfredo Londoño Upegui.

trudante: Doctor Ciro Erasso.

thestesista: doctor Zuluaga.

Vicio: Peso 5 libras y 1/2, con acabalgamiento excesivo de los parietales y un pro deformado; no estaba calcificado, no despedía mal olor.

Post-Operatorio: Normal. Sale del hospital el 5 de noviembre en perfectas ndiviones.

Diacrostico: ¿Embarazo abdominal primitivo o secundario:

Serra ampular, insertado en la franja ovárica, entonces casi totalmente abinal. placenta insertada sobre la trompa, ovario, pared pélvica, porcion pasicrior de la matriz y al epiplón? En este caso, las trompas y ovarios estaban mtw..... luego no parece ampular.

: O. se desurrollaría el huevo hasta el punto de no poder pasar por la trom pa. Ylas vellosidades labrarían un pequeño agujero en la pared tubaria que lo llew al abdomen:

:O. emigraria de la porción intersticial de la trompa por el ostium abdoinal. hacia la quinta semana?

O. seria peritonela primitivo?

Estos tres últimos casos pueden ser posibles en el caso que se presenta.

\section{B I B I O G R A F I A}

1.-Dubrisay (L.): "Precis de Accouchement".

2.-De Lee Greenhilli: "Principios y Práctica de Obstetricia". 